\title{
A trajetória da carreira como construção teórico- prática e a proposta dialética da carreira psicossocial
}

\author{
Marcelo Afonso Ribeiro \\ Departamento de Psicologia Social e do Trabalho do \\ Instituto de Psicologia da Universidade de São Paulo
}

\begin{abstract}
A carreira é um constructo teórico-prático formado por duas dimensões interligadas (administrativa e psicossocial) que surgiu no início do século XX e tem sido estudada pelas ciências da gestão e pelas ciências do trabalho. Foi tradicionalmente associada às empresas e instituições e definida, respectivamente, como carreira organizacional ou desenvolvimento vocacional; e também como não-carreira quando sua forma de construção das trajetórias laborais não atendia a esses modelos. Com a flexibilização, heterogeneização e complexificação do mundo do trabalho ao final do século XX, a carreira sofreu mudanças em sua estrutura, concepção e desenvolvimento, gerando a fragmentação da carreira organizacional e sua ampliação para além dos limites das empresas, alcançando o mundo do trabalho como um todo. O presente artigo, de natureza teórica, teve como objetivo analisar e tentar compreender o que tem sido definido como carreira desde sua gênese e propor alternativas futuras. Como resultado do trabalho, foi reconstruída sinteticamente a trajetória da carreira como um constructo teórico-prático e foram analisadas as principais formas de compreensão e estruturação da carreira já desenvolvidas, sendo proposta uma possibilidade de concepção dialética através do conceito de carreira psicossocial.
\end{abstract}

Palavras-chave: Carreira, Orientação profissional, Dialética, Identidade, Carreira psicossocial.

The course of career as a theoretical and practical concept and the dialectical proposal of a psychosocial career

The career is a theoretical and practical construct formed by two interconnected dimensions (administrative and psychosocial), which emerged at the beginning of the twentieth century and has been studied by the sciences of management and by the sciences of labour. It is traditionally linked to enterprises and is defined, respectively, as organizational career or vocational development, otherwise it is also postulated as non-career all forms of construction of the path through the work that not fit at this model. The world of work has become more flexible, heterogeneous and complex at the end of the twentieth century, which made the career suffer changes in its structure, design and development, leading to fragmentation of the bureaucratic career and its expansion beyond the boundaries of the enterprises, what has impacted the world of work as a whole. This theoretical article aimed to examine and try to understand what has been defined as career since his appearance and assess its future prospects. As a result, it was taken over the trajectory of the career as a theoretical and practical construct and analyzed the main ways of understanding and structuring career that has already been developed. Finally, it was proposed a concept of career based in the dialectics, giving rise to the concept of psychosocial career.

Keywords: Career, Career development, Dialectics, Identity, Psychosocial career.

$\mathrm{O}$ presente artigo, de natureza teórica, teve dois objetivos: retomar e refletir, de modo breve e sintético, o que tem sido definido como carreira em termos de constructo teóricoprático e analisar possibilidades futuras para a concepção e o estudo da carreira através da abordagem dialética, postulando a ideia da carreira psicossocial.

Hughes (1937), considerado um dos primeiros estudiosos da carreira, dizia que ela trazia uma dupla revelação: a) a passagem da pessoa pela vida no trabalho (carreira subjetiva) e b) a constituição e a organização social dessas trajetórias de vida pelas empresas (carreira objetiva), sendo, simultaneamente, um artefato administrativo, com fins pragmáticos de gestão organizacional das pessoas (dimensão administrativa), e um processo social, gerador de identidades, papéis e representações sociais (dimensão psicossocial). 
Essa dupla dimensão foi tradicionalmente dissociada pela ciência que estabeleceu, segundo a divisão proposta por Dejours (1999), de um lado, as ciências da gestão - como o campo de estudos e de intervenção do (e no) trabalho, focada na análise e intervenção da (e na) gestão da organização do trabalho como um todo e interessada na carreira como artefato administrativo (administração e psicologia organizacional) - e, de outro lado, as ciências do trabalho, focadas na análise e na intervenção do (e no) trabalho e das (e nas) relações pessoasorganizações do trabalho, construídas continuamente e interessada na carreira como processo social (psicologia vocacional, sociologia e orientação profissional).

\section{A gênese da ideia de carreira e suas concepções tradicionais}

A concepção de carreira surgiu associada às empresas em um mundo estruturado pela normatividade, pela previsibilidade e pela estabilidade do modelo taylorista-fordista, que se construiu marcado pelas influências da administração científica e da psicometria (Blanch, 2003).

D. T. Hall (2002) aponta que a carreira foi o emblema moderno da trajetória de vida no trabalho por quase todo o século XX, vista como a sequência de empregos ou funções que marcava um progresso através da vida laboral, sendo uma estrutura heterônoma gerida pelas empresas e definida de forma externa, previsível e sequencial - conceito de carreira objetiva (Hughes, 1937), externa (Schein, 1993) ou organizacional (Van Maanen, 1977).

A carreira só existia nas empresas e nas instituições (públicas e privadas) e aqueles que não trabalhassem nesses espaços não tinham o reconhecimento de suas trajetórias de trabalho como carreiras, sendo, em geral, nomeadas como não-carreiras, como era o caso dos profissionais liberais, autônomos, prestadores de serviços ou dos que tinham uma trajetória descontínua de trabalho, apesar de que a muitos profissionais liberais e autônomos era atribuída uma carreira, não pelo vínculo à empresa, mas pela identidade profissional (Super, 1957). Nesse sentido, pode-se dividir as construções da trajetória no mundo do trabalho em:

a) Carreira: estrutura predefinida à qual as pessoas adaptavam-se para construir sua trajetória de trabalho como uma antecipação do futuro e associada a organizações e instituições - lugares em que foi criada e nos quais teria existência e legitimidade social;

b) Não-carreira: significação pos factum da trajetória de trabalho (construção do presente em direção ao futuro) associada ao mundo do trabalho como um todo e, geralmente, não definida como carreira, portanto, sem legitimidade social para tal.

Segundo Gunz e Peiperl (2007), "é muito difícil identificar um padrão organizado no campo de estudos de carreira" (p. 40), que permanece até hoje fragmentado, ainda com lacunas entre os estudiosos da carreira organizacional (ciências da gestão) e da escolha profissional e de desenvolvimento de carreira (ciências do trabalho), apesar de que, em seus estudos, Donald Super, Edgar Schein e Douglas Hall tenham tentado aproximar as áreas.

De qualquer forma, uma sistematização do que já foi produzido faz-se necessária, mesmo correndo-se o risco de reducionismos, discordâncias e imperfeições, porque "os critérios de classificação científica não se aplicam por completo e não podem ser satisfeitos em sua totalidade" (Crites, 1974, p. 30). Gunz e Peiperl (2007) discutem a questão e, através de um mapeamento dos estudos da carreira, indicam uma topologia (níveis de análise da carreira) e uma taxonomia (subcampos de estudos da carreira), conforme vê-se no Quadro 1. 
Quadro 1. Topologia e taxonomia dos estudos de carreira

\begin{tabular}{|l|l|}
\hline \multicolumn{1}{|c|}{ Topologia } & \multicolumn{1}{c|}{ Taxonomia } \\
\hline Individual & $\begin{array}{l}\text { Personalidade, interesses, valores, sucesso, escolha profissional, perfil, carreira interna, } \\
\text { ajustamento vocacional }\end{array}$ \\
\hline Institucional & $\begin{array}{l}\text { Sistemas de carreira, padrões de carreira, contrato psicológico, planejamento e gestão da } \\
\text { carreira }\end{array}$ \\
\hline Contextual & Identidade, estágios e desenvolvimento de carreira, ciclo de vida \\
\hline
\end{tabular}

Percebe-se a pertinência dessa sistematização proposta, nos três modelos tradicionalmente constituídos de análise da carreira descritos na sequência:

a) Modelo de perfil (individual) - auxiliava, operacionalmente, na inserção no trabalho e na construção das carreiras, constituindo-se na base da psicologia vocacional, sendo a carreira definida pelo ajustamento vocacional, visto, por sua vez, de duas formas distintas, como:

- A auto-realização da vocação pelo desempenho de ocupações, na qual pessoas e ocupações eram descritos em termos de um perfil ideal e construíam-se díades definitivas de ajustamento entre elas - Modelo Traço-Fator (Dawis \& Lofquist, 1984; Parsons, 1909/2005; Williamson, 1965);

- A descoberta do tipo de ambiente no qual a pessoa pudesse se expressar, em termos de personalidade e interesses, necessitando de alterações mútuas para o perfeito ajustamento pessoa-ambiente - Modelo Tipológico (Holland, 1997);

b) Modelo estrutural (institucional) - a carreira é vista a partir da estrutura construída pelas empresas (plano de carreira), tendo objetivos operacionais e pragmáticos de auxílio na gestão das pessoas, ao postular um progresso normativo espaço-temporalmente no interior da organização do trabalho - concepção de carreira externa ou objetiva, base para a administração (Dutra, 1996; Hughes, 1937; Schein, 1993);

c) Modelo desenvolvimentista (contextual) - a carreira constituir-se-ia pelo desempenho de uma série de papéis, via comportamento vocacional, processo esse intitulado de desenvolvimento vocacional (subprocesso integrante e decorrente do desenvolvimento pessoal), sendo a base para a construção do autoconceito profissional e para a atualização do compromisso entre fatores individuais e sociais (autoconceito e realidade ocupacional) pelas adaptações sucessivas efetuadas (concepção de carreira interna, Schein, 1993 ou subjetiva, Hughes, 1937). Introduz a ideia da carreira como uma construção psicossocial através da visão funcionalista, sendo a concepção de perfil trocado pela de desenvolvimento e a psicologia vocacional pela psicologia vocacional evolutiva, sendo seu principal autor Donald Super (1957, 1963).

Rivas (2003) aponta que, para Super, a carreira seria um processo de mudança evolutiva ao longo da vida, parte do amplo processo de socialização e determinado pelo comportamento vocacional (conjunto de processos psicológicos que uma pessoa mobiliza em relação ao mundo), no qual a pessoa desenvolve-se no tempo através de aprendizagens e vivências em referência ao meio social, que oferece oportunidades educacionais, laborais e sócio-econômicas, às quais a pessoa engaja-se para sua realização material e humana.

Essas foram as primeiras formas, ainda fragmentadas, de análise da carreira até os anos 1970, início da percepção de que "os estudos de carreira existiam como um campo" (Gunz \& Peiperl, 2007, p. 42), em geral, com as três dimensões de análise apresentadas (individual, institucional e contextual), como vê-se em sistematizações feitas nos últimos vinte e cinco anos por autores tanto nas ciências da gestão, quanto nas ciências do trabalho (Quadro 2). 
Quadro 2. Exemplos de sistematização no estudo das carreiras

\begin{tabular}{|c|c|c|c|}
\hline \multirow[t]{2}{*}{ Autores } & \multicolumn{3}{|c|}{ Níveis de análise } \\
\hline & Individual & Institucional & Contextual \\
\hline Sonnenfeld e Kotter (1982) & Enfoque dos traços & Enfoque da estrutura social & Enfoque do ciclo de vida \\
\hline Arthur e Lawrence (1984) & Diferenças individuais & Estudos organizacionais & Estágios de vida \\
\hline Collin e Young (1986) & Hermenêutico & Ecológico & Biográfico \\
\hline Hall (1987) & Planejamento de carreira & Administração de carreira & Espectro de carreira \\
\hline Gingras et al. (2006) & Circunscrita & Organizacional & Estendida \\
\hline
\end{tabular}

Os enfoques teóricos caminhavam em paralelo, mas não eram relacionados, fazendo com que a carreira fosse explicada através de uma dicotomia entre desenvolvimento vocacional (não vista como carreira) e planos organizacionais de carreira (concepção tradicional de carreira), perfazendo um problema epistemológico crônico, pois, apesar da pluralidade de enfoques, cada um privilegiava um aspecto isolado da questão, perdendo de vista que a carreira é uma construção relacional com uma dualidade ontológica fundante (Silva, 1996).

\section{Avanços nas configurações das carreiras nas últimas décadas}

Com a flexibilização, heterogeneização e complexificação do mundo do trabalho e das empresas ao final do século XX, que ocasionou a ruptura do emprego como modelo hegemônico de inserção no trabalho, a carreira sofreu mudanças em sua estrutura, concepção e desenvolvimento, gerando a fragmentação da carreira organizacional e sua ampliação para além dos limites das empresas e das instituições, alcançando o mundo do trabalho como um todo, fenômeno que levou alguns autores a anunciar o fim da carreira.

D. T. Hall (1996) faz uma alusão a esse panorama no título do seu livro The career is dead - Long live the career, "a carreira está morta", ou seja, a carreira organizacional não é mais o modelo hegemônico e "longa vida à carreira", pois novos modelos surgiram, ampliando suas configurações no mundo do trabalho e gerando novas possibilidades e restrições. Assim, diante dessa situação, a análise da carreira exigiu novos estudos tanto nas ciências da gestão, quanto nas ciências do trabalho.

As ciências da gestão iniciaram um processo de validação de trajetórias de trabalho, antes não consideradas como carreiras (não-carreiras), fora do espaço organizacional, resultando na ruptura parcial dos modelos normativos (planos de carreira ou carreira externa) e dando origem a novas concepções de carreira (Arthur, Hall \& Lawrence, 1989; Blanch, 2003; Gunz \& Peiperl, 2007; Young \& Collin, 2000). São elas:

a) Carreira de Proteu (Protean career): foco na construção individualizada e submetida às demandas do mundo do trabalho, sendo responsabilidade da pessoa seu planejamento, realização e validação (D.T. Hall, 2002);

b) Carreira sem fronteiras (Boundaryless career): foco na relação pessoa-organizações do trabalho como um todo, não só vinculada às empresas, e nos contextos distintos em que a carreira acontece, também nomeada de carreira pós-empresarial ou flexível (Arthur \& Rosseau, 1996; Tolfo, 2002); 
c) Carreira multidirecional ou caleidoscópio: foco na relação pessoa-trabalho, criadora de caminhos diferenciados dentro e fora das empresas (Baruch, 2004);

d) Carreira em espiral: foco nas competências que a pessoa consegue desenvolver e utilizar no trabalho, determinando sua trajetória laboral (Evans, 1986).

Para Schein (1978), a carreira seria uma construção mais dinâmica, gerada na interação e na adaptação mútua das necessidades individuais e organizacionais, acordadas por essa interação e constituindo estruturas mais individualizadas, que contassem com a proatividade tanto do pessoa, quanto das empresas.

As ciências do trabalho também viram-se convocadas a repensar suas concepções sobre carreira, que deveriam ser mais relacionais, por conta da crescente instabilidade do mundo, buscando construir concepções que abarcassem os atuais processos complexos de elaboração das relações pessoa-trabalho (Bohoslavsky, 1983; Super, 1985). Entre elas:

a) Arco-íris de carreira (Life career rainbow): a carreira seria o desenvolvimento da articulação espaço-temporal contínua dos diversos papéis sociais (criança, estudante, tempo livre, cidadão, trabalhador e membro de família) desempenhados por uma pessoa ao longo da vida em uma adaptação recíproca pessoa-sociedade, via papéis, que promoveu, segundo Guichard e Huteau (2001), avanços na teoria de Donald Super, no sentido de responder às demandas instáveis e flexíveis do mundo do trabalho contemporâneo, marcando, via funcionalismo, a importância definitiva da análise psicossocial da carreira (Super, 1980, 1990). Os avanços aparecem na passagem:

- Da maturidade vocacional para a maturidade de carreira (desenvolvimento de estratégias para enfrentar as constantes transições sofridas na carreira) e para a adaptabilidade de carreira (capacidade de mudar e lidar continuamente com as situações novas ou transformadas) (Savickas, 1997);

- Da carreira para a articulação entre os diversos papéis sociais (Super, 1990);

- Das noções de desenvolvimento, progresso e continuidade de carreira para as de transição, processo e descontinuidade de carreira (Super, 1980, 1990);

b) Modelo construtivista e contextual: a carreira seria fruto da ação da pessoa sobre o meio social, que ela conhece e no qual age (agente ativo do seu desenvolvimento) e, simultaneamente, sofre sua influência, em uma explicação contextualista da carreira pela teoria da ação, com base no construtivismo ou no construcionismo social (Young, Valach \& Collin, 2002);

c) Modelo contextual-desenvolvimental: com base no interacionismo, a carreira (desenvolvimento vocacional) seria resultado da interação entre dois processos dinâmicos: o desenvolvimento individual ao longo da vida e o contexto interpessoal, sociocultural e ambiental, complexo e mutante, que gera uma síntese adaptativa das mudanças individuais e sociais que se produzem através da integração e da interação dinâmica entre esse dois processos, difícil de prever a priori, pois ambos estão em transformação constante, na chamada epigênese probabilística (Vondracek, 1990).

\section{Redefinição dos estudos da carreira como constructo teórico-prático}

O desafio contemporâneo nos estudos de carreira requisita uma posição em relação ao mundo que contemple tanto a mudança (movimento), quanto a permanência (essência), pois a mudança sem permanência não eterniza nada e a permanência sem mudança impede $o$ desenvolvimento, discussão clássica entre as filosofias de Parmênides e de Heráclito. 
A partir de uma visão intermediária, é importante compreender que ser e realidade têm uma dimensão estável de permanência e uma dimensão dinâmica de mudança, que convivem em relação constante e estruturante. A permanência existe e é básica, contudo sempre é uma síntese provisória que tem sua existência consolidada até sofrer nova injunção do real que a faz resistir e ficar a mesma ou mudar total ou parcialmente.

A carreira não é somente um reflexo da essência do ser estruturada na realidade (modelo do perfil) nem tampouco um eterno devir em transformação constante (modelo da carreira flexível), ela também pode ser entendida em sua dimensão psicossocial, como já anunciava Super $(1957,1963)$. O mundo do trabalho ampliou-se e complexificou-se, mas não houve uma substituição total de uma panorama pelo outro, ou seja, a carreira ainda é carreira organizacional e novas formas surgiram, que necessitam ser estudadas e analisadas.

Segundo Gunz e Peiperl (2007), a tarefa para os estudiosos da carreira ainda seria "traduzir o entendimento das organizações atuais do trabalho em estruturas com novas formas que melhor atendam as necessidades de um mundo do trabalho complexo e heterogêneo" (Baylin, 1989, p. 480), como apontado décadas atrás, levando em conta os limites dessa tarefa e a importância de redefinir conceitos-chave com base em uma visão mais relacional da carreira, não assumindo uma norma universal, mas analisando possíveis direções de mudança e de desenvolvimento. Como conceituar carreira na atualidade, tendo em vista que as concepções tradicionais parecem não conseguir explicar as suas novas formas?

Diante disso, dois caminhos colocam-se para os estudos de carreira: repensar os estudos das carreiras organizacionais e propor novas formas para sua análise ou alargar o campo de estudo das carreiras de base psicossocial, ou seja, aquelas não construídas no interior de uma empresa, antes nomeadas de não-carreiras, fazendo a proposta de que essas trajetórias no mundo do trabalho também sejam definitivamente chamadas de carreira tanto pelas ciências da gestão, quanto pelas ciências do trabalho, o que ainda não acontece.

O presente artigo optou pela segunda alternativa focando mais na carreira como um processo psicossocial do que um artefato administrativo. Super (1990), Vondracek (1990) e Young, Valach e Collin (2002) já haviam realizado essas tentativas com base no funcionalismo, no interacionismo e no construcionismo social.

Baylin (1989), Sonnefeld e Kotter (1982) e Young e Collin (2000) sugerem que uma forma atual de analisar as carreiras seria pela dialética, assim como Savickas (2002), que não fez um estudo com base na dialética, mas, ao falar da adaptabilidade de carreira, apontava que as "descontinuidades na adaptação psicossocial organizam a dialética do desenvolvimento, que ocorre quando o encontro entre uma tese individual e uma antítese social produz uma nova síntese" (p. 184).

Aceitando o desafio epistemológico e metodológico dos autores citados, será apresentada a proposta da carreira psicossocial, baseada na abordagem dialética, apostando na ideia que essa concepção possa tornar-se, a partir de sua legitimação científica, um enfoque teórico emergente como uma das possíveis explicações para a carreira.

Por que uma abordagem dialética? Se a proposta contemporânea é tentar pensar concepções psicossociais para a carreira "a dialética é um método, através do qual, pode-se compreender a realidade social e também o curso da ação que leva à mudança dessa realidade" (Larsen, 1986, p. 225), pela explicitação das contradições da realidade e dos seus fenômenos, tendo como base a atividade prática concreta do ser histórico.

O método dialético tem como princípio básico que toda concepção nova postulada como síntese deve pressupor concepções anteriores, sendo uma superação delas, que são rejeitadas parcial ou totalmente, pois algo novo (problema que não existia) é confrontado com o conhecimento instituído até aquele momento, instaurando uma contradição entre tese

\section{8}


(concepção anterior) e antítese (problemas e concepções emergentes) para gerar uma nova síntese, que é uma superação da tese anterior, sem ser sua substituição total (Larsen, 1986).

A dialética implica uma estruturação espaço-temporal e histórica em suas sínteses, algo estabiliza-se, não há um fluxo incessante sem nenhuma permanência. As carreiras, como construções psicossociais, seriam sínteses possíveis da relação pessoa-mundo do trabalho, vistas como microestruturas não infinitas, pois o pensamento dialético refere-se ao processo mais do que à estabilidade, entretanto, não nega a formação de estruturas, resultantes do processo de estruturação, desestruturação e formação de novas estruturas.

O contexto atual gera insegurança, mas também oportunidades. Não se deve focar somente na fragmentação causada pela flexibilização da organização do trabalho, mas também olhar para as novas formas de carreira e as novas maneiras de analisá-la.

\section{Possibilidades atuais de concepções de carreira (dimensão direcionada ao futuro)}

Sinteticamente e focando na carreira como processo psicossocial, pode-se indicar quatro alternativas atuais de construção de carreira geradoras de formas distintas de construções identitárias: nostalgia, fechamento, instrumentalidade e possibilidade. Essas nomeações são frutos das relações atuais entre pessoa e mundo sociolaboral, sendo uma proposta de categorização deste artigo, que é didática, mas não tão diferenciada na prática, pois é possível a passagem de uma categoria a outra de acordo com a trajetória de carreira construída pela vicariância das formas identitárias e dos projetos de vida (Guichard, 2000).

\section{Nostalgia}

Sua característica central é a dependência e seria a tentativa de volta a uma ordem passada ou de manutenção de modelos anteriores, em uma modalidade de relação pessoamundo sociolaboral que busca o reforçamento das instituições normativas que legitimassem, novamente, modelos e estruturas hegemônicas, que oferecessem segurança e a inscrição em um sistema de trabalho reconhecido e estável.

A carreira seria marcada pela concepção tradicional focada no contexto (carreira organizacional) e as construções identitárias estariam marcadas pela ideia de identidade como modelo de identificação construído socialmente, através do qual as pessoas moldam suas próprias identidades, em uma relação de dependência institucional, nomeadas por alguns pensadores atuais ${ }^{1}$ como: coletivismo (Castel, 1999), identidade legitimadora (Castells, 1997), formas identitárias estatutárias (Demazière \& Dubar, 2006), sujeito sociológico (S. Hall, 2000) e identidade moderna (Touraine, 1998).

\section{Fechamento}

Sua característica central é a referência ou a resistência e constitui-se na tentativa de ensimesmamento em comunidades delimitadas, por exemplo, por identidades profissionais, na tentativa de proteção contra a flexibilização atual. Está apoiada na autoridade de um grupo de

1 As concepções das construções possíveis da carreira têm base nas principais construções identitárias que estão guiando as referências para as relações pessoa-sociedade na contemporaneidade, descritas por Castel (1999), Castells (1997), Demazière \& Dubar (2006), S. Hall (2000) e Touraine (1998), pensadores do tema na atualidade e cujas ideias foram articuladas no presente artigo, pois, apesar de não serem totalmente justapostas, permitem aproximações e relações genéricas possíveis. 
referência que protegeria a relação pessoa-trabalho, calcada no pertencimento a uma comunidade protetora, por exemplo, os sindicatos.

A carreira, assim, seria definida pelo grupo sociolaboral de referência e por sua respectiva identidade profissional. As construções identitárias seriam sobredeterminadas por essa demanda de pertencimento a um coletivo protetor e podem ser nomeadas como individualismo coletivo (Castel, 1999), identidade de resistência (Castells, 1997), formas identitárias reflexivas ou culturais (Demazière \& Dubar, 2006), sujeito do iluminismo (S. Hall, 2000) e identidade comunitária (Touraine, 1998).

\section{Instrumentalidade}

Adere ao discurso do eterno devir heraclitiano e não estabelece nenhuma estrutura ou modalidade de relação coletiva, desaparecendo ao concretizar-se e sendo singular no seu extremo, visando somente uma adaptação às demandas do mundo do trabalho, sem vínculo, nem permanência, nem constituição de identidade, o que impediria qualquer tentativa de análise para além da compreensão individual das carreiras, como nos parece propor a concepção contemporânea de carreira focada na pessoa (carreira de Proteu) ou na multiplicidade de contextos e funções (carreiras sem fronteiras).

Em termos de construção identitária, caracteriza-se por ser uma adaptação identitária instrumental aos processos de trabalho, sem escolha ou autonomia, pois seria um processo contínuo marcado pela não-permanência, transitoriedade e uso instrumental da relação com o mundo (estratégia identitária de difusão adaptativa), fixando uma crise do laço social (Dubar, 2000), apesar de ser uma construção psicossocial.

Para Certeau (1994), esse é o mundo das táticas, que prende as pessoas na temporalidade presente e reduz sua ação ao momento de agir, pois não transforma as resultantes da ação em recurso disponível para si, em função de sua perenidade: "a tática só tem por lugar o [lugar] do outro" (p. 46), aprisionando as pessoas às circunstâncias, sem chance de apropriação. Essas construções identitárias podem ser nomeadas de individualismo negativo (Castel, 1999), formas identitárias de difusão adaptativa (Demazière \& Dubar, 2006), sujeito pós-moderno (S. Hall, 2000) e identidade estratégica ou pós-moderna (Touraine, 1998).

\section{Possibilidade}

Sua característica central é a noção de projeto (discutida a seguir) e, como a própria nomeação atribuída propõe, aponta um caminho de análise intermediário da carreira que não aposte na estabilidade permanente de uma estrutura hegemônica e genérica nem na mudança incessante de estruturas singulares não-intercambiáveis, mas, antes, em microestruturas construídas coletivamente através de estratégias, submetidas às injunções do real, que, ao mesmo tempo que as transformam, possibilitam a emergência de padrões heterogêneos e múltiplos, mas não infinitos, de carreira, em uma concepção focada na relação pessoa-mundo do trabalho.

Segundo Certeau (1994), a estratégia permitiria a gestão das relações com a exterioridade distinta (real do trabalho) pela produção de lugares próprios. Em termos de construções identitárias, elas podem ser nomeadas como individualismo moderno (Castel, 1999), identidade de projeto (Castells, 1997), formas identitárias narrativas (Demazière \& Dubar, 2006) e sujeito (Touraine, 1998).

De um lado, tem-se as categorias nostalgia e fechamento, que pressupõem uma adaptação a uma estrutura sociolaboral ou grupo socioprofissional predefinidos (foco na dimensão institucional), que diminuem as chances de transformação relacional recíproca pela 
tentativa de estabilidade. Para Guichard (2000), o projeto profissional estaria aí marcado por uma identificação aos quadros identitários constituídos e levaria a pessoa a conservar a estrutura instituída em uma estabilidade subjetiva ou pela cristalização identitária.

Por outro lado, tem-se a instrumentalidade e a possibilidade como categorias construídas na relação e na constante transformação recíproca, não configurando modelos estáveis, mas sínteses temporárias como modelos transitórios (foco na relação pessoa-trabalho), sendo uma possível análise do futuro das carreiras, como na carreira psicossocial.

Segundo Certeau (1994), ambas são construções relacionais, mas a instrumentalidade constituir-se-ia em uma tática, vinculada à dimensão presente e com uma dificuldade inerente de permanência, sendo marcada pela mudança constante, muitas vezes sem gerar sentido ou história no trabalho, enquanto que a possibilidade seria uma estratégia, ligada à apropriação do futuro e à geração de sentido e de história para a carreira.

Para Guichard (2000), o projeto profissional, nestes casos, estaria marcado por uma forma identitária subjetiva que levaria a pessoa a realizar uma construção de si nos quadros identitários instituídos, em uma maleabilidade subjetiva ou vicariância identitária constante.

\section{A concepção da carreira psicossocial (perspectiva de dimensão futura)}

A contemporaneidade apresenta uma situação que é marcada mais pela instabilidade e pela mudança do que pela estabilidade e pela permanência, constituindo novas formas de espacialidade e de temporalidade, para além das formas tradicionais, ressaltando a importância do tempo e do espaço para a construção da memória, do planejamento e da própria experiência de vida, necessários à construção de papéis, lugares, identidades e representações sociais, através das práticas sociais (Young \& Collin, 2000).

Tradicionalmente, o espaço era visto como estrutura permanente ou produto estável e previsível da relação psicossocial (projeto de estado, Barbier, 1996), objetivo, conhecido e legitimado socialmente, e poderia ser definido como lugar, que seria uma configuração estável de posições na qual se distribuem os elementos nas relações de coexistência (Certeau, 1994; Ribeiro, 1999).

O tempo, definido pela temporalidade de Chronos, era visto como linear, previsível e base do calendário que permitia o planejamento do cotidiano (tempo de pensar), nomeado de time (Pelletier, 2001).

Essa organização espaço-temporal instaurava um mundo conhecido, definido pela repetição e pela ordem, o qual a pessoa apreendia pelo conhecimento e no qual a operação da relação pessoa-mundo era de adaptação a um mundo que se conhecia, que oferecia uma referência a ser seguida e no qual se encontravam produtos e estruturas aos quais se deveria adaptar, ou seja, há o consumo de táticas, sendo a fabricação do cotidiano um processo de reprodução (Certeau, 1994) - esse era o mundo das carreiras organizacionais que demandavam estabilidade na organização espaço-temporal.

Com a crescente instabilidade do mundo atual, a espacialidade e a temporalidade sofreram mudanças significativas. $\mathrm{O}$ espaço, antes entendido apenas como lugar, enquanto estrutura permanente e estável, não é mais só isso, mas, antes, define-se pela construção recíproca entre pessoa-mundo, ou seja, o lugar institucionalizado transforma-se parcialmente em lugar praticado ou espaço (Certeau, 1994), no qual se fundaria a relação psicossocial, mais processo (projeto de ação, Barbier, 1996) do que produto. 
O tempo, antes baseado em Chronos, altera-se parcialmente para a temporalidade de Kairós (tempo inédito, descontínuo, marcado pela novidade e pela ruptura), nomeado de timing (Pelletier, 2001).

Essa organização espaço-temporal instaura um mundo que não é para ser conhecido, pois não mais seria definido pela repetição e pela ordem, mas sim um mundo para se agir, no qual não é mais possível adaptar-se, mas sim colocar em ação um processo contínuo de construção da relação psicossocial, instaurador de um fio condutor que indica um percurso a ser trilhado (processo) e não um resultado a ser alcançado (produto). Esse é o mundo das carreiras psicossociais, vistas como microestruturas heterogêneas de carreira que demandam uma construção contínua da relação psicossocial através de sínteses temporárias e precisam ser legitimadas socialmente.

A carreira seria uma trajetória, definida por Certeau (1994) como um "movimento temporal no espaço, isto é, a unidade de uma sucessão diacrônica de pontos percorridos, e não a figura que esses pontos formam num lugar supostamente sincrônico ou acrônico" (p. 98).

Em um mundo instável e construído em relação, projetos de natureza Chronos (trajetória com destinação precisa ou figura, Certeau, 1994) não atendem a todas as demandas da relação psicossocial, sendo necessário constituir projetos de natureza Kairós, que reconhecem a impossibilidade de antecipação precisa da destinação e focam sua base no processo de construção da carreira (sucessão na trajetória, Certeau, 1994).

Assim, as pessoas não se adaptariam a uma estrutura de coisas predefinidas ou projeto social coletivamente instituído (carreira organizacional), mas teriam a capacidade de transformar as incertezas do contexto atual em espaços legíveis traduzidos em construções de carreiras operadas na relação psicossocial (carreira psicossocial), que permitiriam lidar com a variabilidade das circunstâncias, sem ficar presas a elas na temporalidade do presente, situação que impediria o futuro.

As carreiras seriam determinadas pelas práticas cotidianas, com uma orientação em termos de processo, mas não mais uma destinação pré-existente, sendo essas práticas produtos legitimados de um trabalho coletivo, nesse sentido, não existiriam carreiras individuais nem modelos hegemônicos de carreiras, mas sim modelos finitos e heterogêneos, construídos em relação e legitimados socialmente, pois "todo lugar 'próprio' é alterado por aquilo que, dos outros, já se acha nele” (Certeau, 1994, p. 110).

As pessoas não teriam uma carreira, como tradicionalmente dizia-se da carreira como projeto social coletivo e acabado ao qual se adaptava, incorporando esse produto social como próprio, mas seriam sujeitos de projetos, ou seja, construiriam trajetórias no mundo do trabalho, marcando seus projetos individuais de vida no trabalho, entretanto, esses projetos teriam que ter legitimidade social, pois carregariam em si modelos já constituídos na relação psicossocial.

A carreira construída em um contexto em mudança constante não pode ser somente definida como algo onde nada permanece, pois esse é o reino da instrumentalidade, mas, antes, deve ter a potencialidade de relação e de transformação, e de gerar sentido e continuidade, como preconiza o campo da possibilidade.

Para Certeau (1994), as práticas cotidianas são artes de fazer, nas quais se reconhece uma arte de pensar, mas, antes disso, são artes de dizer, que é "um dizer sobre aquilo que o outro diz de sua arte, e não um dizer dessa arte" (p. 151). Pode-se dizer que as carreiras, em um mundo em transição e instável, são construções relacionais que antes de tornarem-se práticas legitimadas socialmente, constituem-se como atividades narrativas sobre o que se faz (processo) e, dessa forma, "se a própria arte de dizer é uma arte de fazer e uma arte de pensar, pode ser ao mesmo tempo a prática e a teoria dessa arte" (Certeau, 1994, p. 152).

As maneiras de fazer designam atividades, e a sua construção, em um campo no qual também se desenvolve a produção de uma teoria, sendo que a atividade narrativa das práticas 
cotidianas permitiria relacionar as teorias com as operações das quais é efeito pela compreensão dessa narração, pela determinação de organizações espaço-temporais, pela descrição e pela fundação dessas organizações e por sua posterior autorização social: a carreira seria uma das práticas cotidianas, que fundam organizações espaço-temporais que, pela legitimação social, podem ser nomeadas de carreira ou carreira psicossocial, como proposta.

Antes de ser carreira, ela é um projeto psicossocial de carreira, não planejado a priori, mas construído nas relações psicossociais pelas práticas cotidianas. As carreiras, enquanto projetos, fundam espaços na relação com os lugares socialmente constituídos através de estratégias construídas nas relações psicossociais e legitimadas por essas relações, pois "o lugar é o locus no qual o espaço pode ser criado e ganhar status de corporeidade" (Ribeiro, 1999, p. 69), ou seja, não há a constituição de espaço nem da carreira sem o outro como referente, afinal as práticas cotidianas, como as práticas do trabalho, acontecem na relação entre eu-outro-real (Dejours, 1999) e são definidas por objetos que fundam lugares e operações geradores de espaços pelas ações das pessoas.

A noção de projeto é polissêmica e produz uma ambiguidade ontológica, pois se constitui, ao mesmo tempo, em resultado a ser alcançado (produto) ou projeto de estado; ou encadeamento de ações a ser realizado (processo) ou projeto de ação.

Barbier (1996), ao diferenciar um projeto de estado de um projeto de ação, diz que o projeto de estado produziria uma representação relativa ao estado final (realidade transformada) do que se pretende transformar, constituindo-se em uma antecipação de um estado, enquanto o projeto de ação produziria uma representação relativa ao processo que permitiria chegar a esse estado final, constituindo-se em uma antecipação de um processo.

Como projeto de ação, a noção de projeto tem um lugar central no campo da renovação das práticas sociais, pois não é a simples representação da antecipação do futuro e sim uma antecipação que tem efeito operatório, ou seja, não é previsão do futuro, mas um futuro a fazer na relação dialética pessoa-sociedade, sendo um dizer (projeto como representação, com efeito operatório) que prepara o fazer (escolhas e ações finalizadoras).

Um projeto de ação só se caracteriza como tal por ser um projeto de ação socializado, construído na relação psicossocial e, por isso, carrega em sua estrutura elementos já constituídos das práticas sociais cotidianas e pode ser compartilhado, transformando-se, assim, em um discurso social legitimado, fundador de ações psicossociais concretas, como as carreiras, que se tornam microestruturas constituídas em relação pela ação recíproca entre sujeito da ação e realidades consolidadas.

Essas microestruturas ou projetos de ação socializados ou, como foi aqui nomeado, carreiras psicossociais, são sínteses temporárias de trajetórias no mundo do trabalho que são utilizadas como modelos para a construção de novas formas de carreira (representações existentes de processos), sendo uma representação orientando o real e não uma representação orientada do real, como o modelo da carreira organizacional. Dessa forma, a carreira como projeto de ação socializado é determinada por relações sociais que lhe são prévias e, ao mesmo tempo, é o espaço suplementar para o estabelecimento dessas relações.

E, como tal, a carreira seria um instrumento de dinamização dos processos de transformação tanto da estrutura social (papéis e representações sociais), quanto da estrutura subjetiva (self e identidades psicossociais), que não são estruturas separadas, mas sim polos extremos de um mesmo elo de continuidade.

Essa concepção permitiria pensar, ao mesmo tempo, nos processos de transformação do real, nas condições psicossociais dessa transformação e nas realidades emergentes desse processo, saindo das estruturas e voltando ao campo das práticas sociais, pois, atualmente, os processos de construção seriam mais importantes do que os resultados já instituídos (produtos), perfazendo uma produção dialética contínua. 


\section{Considerações finais}

O presente artigo teve três resultados:

a) A delimitação da trajetória da carreira como um constructo teórico-prático, que partiu de um padrão mais normativo e estável (carreira como produto) para atingir um forma mais relacional e psicossocial (carreira como processo), sendo que, em geral, as possíveis sistematizações dos estudos de carreira têm sido classificadas a partir de três dimensões de análise (individual, institucional e contextual);

b) A categorização dos resultados das relações atuais entre pessoa e mundo do trabalho em quatro maneiras de construção de carreira geradoras de formas distintas de construções identitárias (nostalgia, fechamento, instrumentalidade e possibilidade);

c) A postulação da concepção de carreira psicossocial através da dialética, que é uma das opções ainda pouco exploradas no estudo das carreiras e que abarca em seu bojo a análise psicossocial, como já haviam, tradicionalmente, proposto autores como Douglas Hall, Edgar Schein e Donald Super, e, mais recentemente, Audrey Collin, Mark Savickas e Richard Young. A carreira psicossocial, enquanto microestrutura ou projeto de ação socializado, pode ser compreendida como uma relação dialética entre projeto social (estrutura objetiva) e projeto de vida de cada pessoa (estrutura subjetiva), entendendo projeto como uma articulação entre individual e social, concretizados pelas trajetórias de vida (deslocamentos espaços-temporais) tanto das pessoas, quanto das organizações do trabalho, vistos como fenômenos psicossociais legitimados e compartilhados.

As pessoas na contemporaneidade, segundo a categorização apresentada (item b acima), poderiam ter dois caminhos: o da busca do ajustamento ou da adaptação mais definidos e estáveis (categorias da nostalgia ou do fechamento) ou a ação de construção relacional entre pessoa-mundo do trabalho (categorias da instrumentalidade ou da possibilidade), sendo que a carreira psicossocial seria uma síntese temporária dessa relação que pode levar a uma apropriação da carreira (possibilidade) ou a uma relação instável e transitória que dificultaria essa apropriação (instrumentalidade).

A concepção da carreira psicossocial não responde por todas as construções de carreira da atualidade e deve ser testada empiricamente com mais profundidade para ser validada como enfoque teórico emergente, entretanto, mostra-se como uma primeira apresentação pública da concepção para o início de uma interlocução com a comunidade científica dedicada ao tema da carreira e do mundo do trabalho como um todo.

\section{Referências}

Arthur, M. B. \& Lawrence, B. S. (1984). Perspectives on environment and career: an introduction. Journal of Occupational Behavior, 5, 1-8.

Arthur, M. B. \& Rosseau, D. M. (1996). The boundaryless career: a new employment principle for a new organizational era. New York: Oxford University Press.

Arthur, M. B., Hall, D. T. \& Lawrence, B. S. (Eds.). (1989). Handbook of career theory. Cambridge: Cambridge University Press.

Bailyn, L. (1989). Understanding individual experiences at work: comments on the theory and practice of careers. In M. B. Arthur, D. T. Hall \& B. S. Lawrence (Eds.), Handbook of career theory (pp. 477-489). Cambridge: Cambridge University Press.

Barbier, J. M. (1996). Elaboração de projectos de acção e planificação. Porto: Porto. 
Baruch, Y. (2004). Transforming careers: from linear to multidirectional career paths: organizational and individual perspectives. Career Development International, 9 (1), 58-73.

Blanch, J. M. (Org.). (2003). Teoría de las relaciones laborales. Barcelona: UOC.

Bohoslavsky, R. (1983). Vocacional: teoria, técnica e ideologia. São Paulo: Cortez.

Castel, R. (1999). As metamorfoses da questão social: uma crônica do salário (2ª ed.). Petrópolis: Vozes.

Castells, M. (1997). The power of identity (The information age: economy, society and culture) II. Oxford: Blackwell.

Certeau, M. (1994). A invenção do cotidiano: artes de fazer (vol. 1). Petrópolis: Vozes.

Crites, J. O. (1974). Psicología vocacional. Buenos Aires: Paidós.

Dawis, R. V. \& Lofquist, L. H. (1984). A psychological theory of work adjustment. Minneapolis: University of Minnesota Press.

Dejours, C. (1999). Conferências brasileiras. São Paulo: FGV.

Demazière, D. \& Dubar, C. (2006). Trajetórias profissionais e formas identitárias: uma teorização. In N. A. Guimarães \& H. Hirata (Orgs.), Desemprego: trajetórias, identidades, mobilizações (pp. 165-187). São Paulo: SENAC.

Dubar, C. (2000). La crise des identité: l'interprétation d'une mutation. Paris: PUF.

Dutra, J. S. (1996). Administração de carreira. São Paulo: Atlas.

Evans, P. (1986). Directions in career management. Personnel Management, 18 (12), 26-29.

Gingras, M. et al. (2006). Carrière, un concept en évolution. Carriérologie, 10 (3), 412-425.

Guichard, J. (2000). Cadres et formes identitaires vicariantes et pratiques en orientation. L'Orientation Scolaire et Professionnelle, 29 (1), 181-212.

Guichard, J. \& Huteau, M. (2001). Psicologia da orientação. Lisboa: Instituto Piaget.

Gunz, H. P. \& Peiperl, M. A. (2007). Handbook of career studies. Thousand Oaks: Sage.

Hall, D. T. (1987). Career development in organizations. San Francisco: Jossey-Bass.

Hall, D. T. (1996). The career is dead: long live the career. San Francisco: Jossey-Bass.

Hall, D. T. (2002). Careers in and out of organizations. Thousand Oaks: Sage.

Hall, S. (2002). A identidade cultural na pós-modernidade. Rio de Janeiro: DP\&A.

Holland, J. L. (1997). Making vocational choices (3를 ed.). Englewood Cliffs: Prentice-Hall.

Hughes, E. C. (1937). Institutional office and the person. American Journal of Sociology, 43, 404-413.

Larsen, K. S. (Org.). (1986). Dialectics and ideology in psychology. Norwood: Ablex.

Parsons, F. (2005). Choosing a vocation. Boston: Houghton. (Original publicado em 1909)

Pelletier, D. (2001). Pour une approache orientante de l'école québécoise: concepts et pratiques à l'usage des intervenants. Québec: Septembre.

Ribeiro, M. A. (1999). Espaço urbano: o silêncio ruidoso das ruas. Unicsul, 4 (5), 68-74.

Rivas, F. (2003). Asesoramiento vocacional. Barcelona: Ariel.

Savickas, M. L. (1997). Career adaptability: an integrative construct for life-span, life-space theory. Career Development Quarterly, 45 (3), 247-259.

Savickas, M. L. (2002). Career construction. In D. Brown et al. (Eds.), Career choice and development (4ª ed., pp. 149-205). San Francisco: Jossey-Bass.

Schein, E. H. (1978). Career dynamics: matching individual and organizational needs. Reading: Addison-Wesley.

Schein, E. H. (1993). Career anchors: discovering your real values. Amsterdam: Pfeiffer.

Silva, L. B. C. (1996). A escolha da profissão: uma abordagem psicossocial. São Paulo: Unimarco.

Sonnenfeld, J. \& Kotter, J. (1982). Maturation of career theory. Human Relations, 35 (1), 19-46.

Super, D. E. (1957). The psychology of careers. New York: Harper \& Row.

Super, D. E. (1963). Career development: self-concept theory. New York: CEEB. 
Super, D. E. (1980). A life-span, life-space approach to career development. Journal of Vocational Behavior, 16, 282. 298.

Super, D. E. (1985). New dimensions in adult vocational and career counseling. Occasional paper (n. 106). Ohio: The National Center for Research in Vocational Education.

Super, D. E. (1990). A life-span, life-space approach to career development. In D. Brown \& L. Brooks (Eds.), Career choice and development (pp. 28-42). San Francisco: Jossey-Bass.

Tolfo, S. R. (2002). A carreira profissional e seus movimentos: revendo conceitos e formas de gestão em tempos de mudança. Psicologia: Organização e Trabalho, 2 (2), 39-63.

Touraine, A. (1998). Poderemos viver juntos? Iguais e diferentes. Petrópolis: Vozes.

Van Maanen, J. (1977). Organizational careers: some new perspectives. New York: Wiley.

Vondracek, F. W. (1990). A developmental-contextual approach to career development research. In R. A. Young \& W. A. Borgen (Eds.), Methodological approaches to the study of career. New York: Praeger Publishers.

Williamson, E. G. (1965). Vocational counseling. New York: McGraw-Hill.

Young, R. A. \& Collin, A. (1986). New directions for theories of career. Human Relations, 39 (9), 837-853.

Young, R. A., Valach, L. \& Collin, A. (2000). A contextualist explanation of career. In D. Brown et al. (Eds.), Career choice and development (4⿳亠丷厂 ed., pp. 206-252). San Francisco: Jossey-Bass.

Young, R. A. \& Collin, A. (Eds.). (2000). The future of career. Cambridge: Cambridge University Press.

\section{Endereço para correspondência \\ marcelopsi@usp.br}

Recebido em: 02/09/2008

Revisado em: 25/11/2008

Aprovado em: 10/12/2008 